\title{
Esophageal Stricture Post Accidental Corrosive Ingestion: A Case Report
}

\author{
Joshi BG ${ }^{1}$, Lamichhane $\mathbf{R}^{2}$, Ghimire $\mathbf{M}^{3}$
}

${ }^{1}$ Dr. Binita Gurubacharya Joshi, MBBS, MD, ${ }^{2}$ Dr. Ritu Lamichhane, MBBS, MD, ${ }^{3}$ Dr. Madhu Ghimire, Consultant Gastroenterologist. All from the Norvic Hospital, Thapathali, Kathmandu, Nepal.

\section{Address for correspondence:}

Dr. Binita Guribacharya Joshi

E-mail: bonitajoshi9@gmail.com

\section{How to cite}

Lamichhane R, Joshi BG. Esophageal Stricture Post Accidental Corrosive Ingestion: A Case Report. J Nepal Paediatr Soc 2016;36(3):291294. 
4-6 weeks after initial ingestion. Strictures refractory to dilatation should undergo surgery ${ }^{10}$.

\section{The Case}

A five years old girl from Baglung district had accidental ingestion of corrosive, namely Methyl orange at her school 16 months back. Soon after ingestion she was noted with swelling of lips and tongue followed by drooling and acute onset of epigastric pain. Immediately she was referred to tertiary hospital. Upon examination, there was note of erosion of lower lip, dorsum of tongue and floor of mouth with mild tenderness at epigastric region, with normal vitals and other systemic examination. Supportive treatment was given and was discharged after 12 days with good oral intake. However, vomiting started soon after discharge which became persistent hence was referred to tertiary hospital in Kathmandu. A barium follow through was done with suspicion of esophageal/ gastric stricture which was normal. UGI endoscopy was also performed which showed esophageal stricture and was referred to
India for further management

There in India, she was admitted under pediatric gastrointestinal unit where a repeat endoscopy was performed showing two strictures at $11 \mathrm{~cm}$ and another at $15 \mathrm{~cm}$, latter showed ulceration. Subsequently guide wire was placed and NJ tube inserted for feeding. She underwent multiple esophageal dilatations of stricture after that. As there was no relief, gastrostomy was performed by pediatric surgeon. Subsequently, barium swallow was done still showing narrowing of esophagus and dilatation could not be done as planned due to presence of bleeding non healing ulcer at stricture site. Patient then underwent esophageal strictuloplasty with end to end anastomosis.Gastrograffin study showed normal flow following surgery. However, after three weeks of discharge vomiting started. UGI endoscopy revealed anastomotic site narrowing, again requiring esophageal dilatation. She underwent multiple dilatations in 15 days interval. Patient was then referred back to Nepal at our center for subsequentesophageal dilatation since the facility was already available here.

\section{Endoscopic view 9 months after the last dilatation}

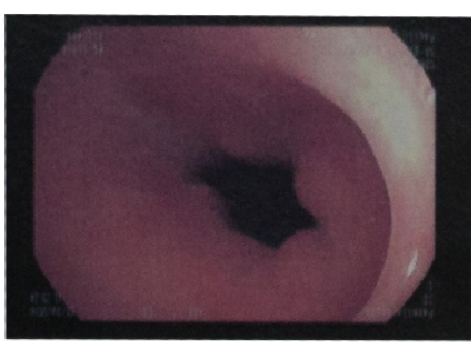

Slight narrowing of esophagus seen at $15 \mathrm{~cm}$ from incisor

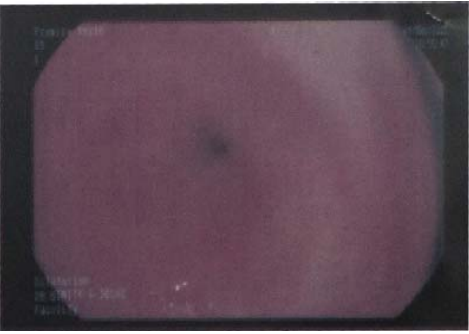

Esophageal stricture at $15 \mathrm{~cm}$ from incisor

\section{Esophageal stricture dilatation}
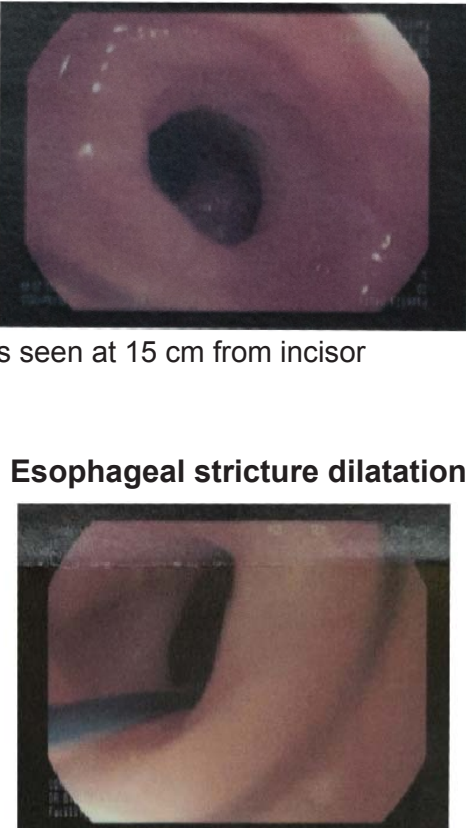

Guidewire placed across the stricture

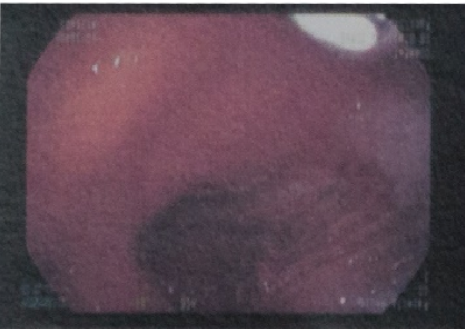

No difficulty in passing scope from esophagus to stomach

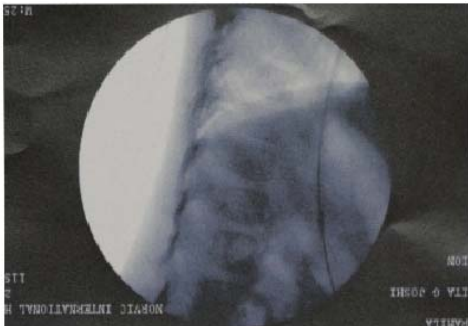

Fluoroscopic appearance of guidewire

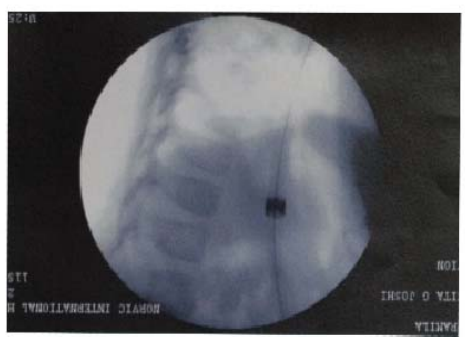

Savary Gillard dilator passed accross guidewire

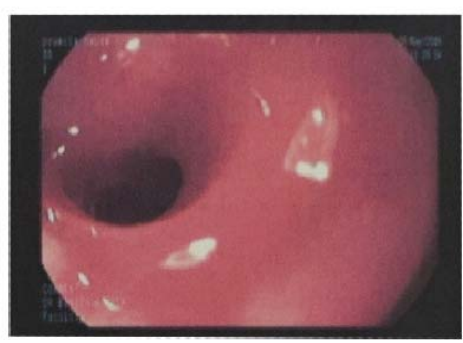

Esophageal stricture post dilation 
In our hospital, multiple serial dilatations were done using Savary Gillard dilator under fluoroscopic guidance, initially at 15 days interval then one month and three months intervals. Gastrostomy tube was removed subsequently and was fed orally which was tolerated. Our patient is the first to undergo esophageal dilatation for stricture in children in our country.

At present, she has good oral intake and is asymptomatic with weight gain of three kilograms.

\section{Discussion}

Children amount to $80 \%$ of ingestion injury globally ${ }^{1,5,7}$.Most ingestions are due to parent's lack of knowledge of the hazards of corrosive substances kept in the house, and the availability of chemicals in and around houses, combined with the natural curiosity of children ${ }^{3}$. Acids and alkali are two primary types of agents responsible for corrosive exposures ${ }^{1}$. Each produce different types of tissue damage ${ }^{7}$. In general alkaline substances tend to be more palatable than acidic products resulting in ingestion of larger quantities and increased risk of serious injury ${ }^{10}$. Acids cause coagulation necrosis with eschar formation that may limit substance penetration and injury depth. Conversely alkalis combine with tissue proteins and cause liquefactive necrosis, saponification of fats, dehydration of tissues and thrombosis of blood vessels resulting in deeper tissue injury ${ }^{4,7,9,11,12}$.

Clinical presentations are very diverse and initial symptoms do not show deep correlation with ultimate degree of injury ${ }^{5}$. Clinical manifestation may vary from no symptoms to nausea, vomiting, drooling, abdominal pain, dysphagia, odynophagia, chest pain or stridor. There may be damage in the esophagus or stomach even if oropharyngeal examination is normal or patient is asymptomatic ${ }^{6}$. Fever, palpitations, shock indicate extensive damage ${ }^{7}$.

Initial management involves stabilizing the patient by keeping nil per oral, vigorously replacing volume and securing airway. Imaging should be done to rule out perforation of esophagus and stomach 5,7 Esophagogastroduodenoscopy is crucial and usually recommended in the first 12-24 hours after corrosive ingestion once perforation has been ruled out, however, some reports indicate it can be safely performed upto 96 hours after ingestion ${ }^{7,9,10}$. The endoscopic grading of injuries is not only to evaluate esophageal and gastric injuries but also predict prognosis and establish a management plan. Grade 0 indicates normal mucosa; Grade I indicates slight swelling and erythema; Grade Ila indicates presence of superficial ulcers, bleeding and exudates; Grade IIb indicates local or encircling deep ulceration; Grade IIla indicates focal necrosis; and Grade IIIb indicates extensive, circumferential necrosis ${ }^{1,5,7,10}$. Gastric lavage and induced emesis are contraindication ${ }^{1,4,7,10}$.Nasogastric or Nasojejunostomy tube should be placed under direct endoscopic vision for feeding purpose $\mathrm{e}^{5,10}$. Emergent surgery is recommended if there is evidence of perforation ${ }^{5}$. Patients with grade 0 injuries can be discharged immediately. Those with grade I or Iladonot require specific treatment. Patient with gradell must be carefully observed for perforation symptoms for at least 1 to 2 weeks in intensive care unit and adequate nutritional support is required ${ }^{5}$. Gastrostomy may be required for Grade IIIb lesions for nutritional support ${ }^{1,3}$. Other supportive measures include broad spectrum IV antibiotics, PPI, antacid. Although the use of systemic steroid in treatment of corrosive esophagitis remains controversial, some reports have documented the advantage of high dose systemic steroid administration for prevention of stricture formation ${ }^{13}$. Long term sequel include esophageal or gastric stricture usually after 3 weeks ${ }^{1}$. The rate of stricture formation is reported to be between $2 \%$ and $63 \%{ }^{14}$. Pyloric stenosis and gastric outlet obstruction can also occur following corrosive ingestion ${ }^{10}$. Endoluminal dilatation is the management of choice in children $n^{4,10,15}$ which can be done endoscopically by either a bougie or balloon catheter ${ }^{16}$. After initial injury, it is advisable to wait for 3 to 6 weeks prior attempting dilatation ${ }^{11}$. For dilatation, progressively larger bougies are inserted over endoscopically placed guidewires ${ }^{1}$. Esophageal replacement surgery becomes necessary for those refractory one ${ }^{10}$. However, balloon dilatation or endoscopic bouginage is still necessary for recurrence of stricture post surgery ${ }^{15}$, like in our case presented.

\section{Conclusion}

Corrosive ingestion possesses a potential public health risk and widespread lack of knowledge regarding the harmful effects and preventive measures remains important risk factor for these injuries. Education is important to spread awareness of dangers associated, also its use should be regulated in order to reduce or prevent such injuries. 


\section{References}

1. Naik RR, Vadivelan M. Corrosive Poisoning. Indian J Clinic Pract 2012;23:131-34.

2. Hurtado CE, Kramer RE. Salicylic acid ingestion leading to esophageal stricture. PediatrEmerg Care 2010;26(2):146-8.

3. Contini S, Swarray-Deen A, Scarpignato C Oesophageal corrosive injuries in children: a forgotten social and health challenge in developing countries. Bull World Health Org 2009;87(12):950-4.

4. Riffat $F$, Cheng A. Pediatric caustic ingestion: 50 consecutive cases and a review of the literature.Dis Esophagus 2009;22(1):89-94.

5. Park KS. Evaluation and management of caustic injuries from ingestion of Acid or alkaline substances. ClinEndosc 2014;47(4):301-7.

6. Urganci N, Usta M, Kalyoncu D, Demirel E. Corrosive substance ingestion in children. Indian $J$ Pediatr 2014;81(7):675-9.

7. Contini S, Scarpignato C. Caustic injury of the upper gastrointestinal tract: a comprehensive review. World J Gastroenterol 2013;19(25):3918-30

8. Betalli P, Falchetti D, Giuliani S, Pane A, Dall'Oglio L, et al. Caustic ingestion in children: is endoscopy always indicated? The results of an Italian multicenter observational study. GastrointestEndosc 2008;68(3):434-9.
9. Mas E, Breton A, Lachaux A. [Management of caustic esophagitis in children]. Arch Pediatr2012;19(12):13628.

10. Shub MD. Therapy of caustic ingestion: new treatment considerations. CurrOpinPediatr 2015;27(5):609-13.

11. Keh SM, Onyiioc N, McManus K, McGuigan J. Corrosive injury to upper gastrointestinal tract: Still a major surgical dilemma. World J Gastroenterol 2006;12(32):5223-8

12. Karaman I, Koç $O$, Karaman A, Erdoğan D, Çavuşoğlu YH, et al. Evaluation of 968 children with corrosive substance ingestion.Indian J Crit Care Med 2015;19(12):714-8.

13. Morikawa N, Honna $\mathrm{T}$, Kuroda $\mathrm{T}$, Watanabe $\mathrm{K}$, Tanaka $\mathrm{H}$, Takayasu $\mathrm{H}$, et al. High dose intravenous methylprednisolone resolves esophageal stricture resistant to balloon dilatation with intralesional injection of dexamethasone.PediatrSurglnt 2008;24(10):11614.

14. Temiz A, Oguzkurt P, Ezer SS, Ince E, HicsonmezA.. Predictability of outcome of caustic ingestion by esophagogastroduodenoscopy in children.World J Gastroenterol 2012;18(10):1098-103.

15. Lee HJ, Lee JH, Seo JM, Lee SK, Choe YH. A single center experience of self-bougienage on stricture recurrence after surgery for corrosive esophageal strictures in children. Yonsei Med J 2010;51(2):202-5.

16. Poddar U, Thapa BR. Benign esophageal strictures in infants and children: results of Savary-Gilliard bougie dilation in 107 Indian children. GastrointestEndosc 2001 ;54(4):480-4. 